\title{
Measuring Learner Satisfaction with Formative e-Assessment Strategies
}

\author{
https://doi.org/10.3991/ijet.v14i07.9120 \\ Bernard Bahati $(\bowtie)$ \\ University of Rwanda, Kigali, Rwanda \\ bahatib@dsv.su.se \\ Uno Fors, Preben Hansen, Jalal Nouri \\ Stockholm University, Stockholm, Sweden \\ Evode Mukama \\ University of Rwanda, Kigali, Rwanda
}

\begin{abstract}
The Student experience with different aspects of online instructional settings has been the focus of educational practitioners and researchers in many studies. However, concerning technology-enabled formative assessment, little is known about student satisfaction regarding different possible formative e-assessment strategies students are involved in. Using a 5-point Likert scale questionnaire, a web-based survey was developed to examine students' satisfaction with the formative e-assessment strategies within an enriched virtual blended course. The results show that, in general, the students were satisfied with the quality of their engagement and the quality of feedback across all the formative e-assessment learning activities. The results also show that the student satisfaction varied between and within the formative e-assessment strategies. However, the gap between the student satisfaction mean ratings across all formative e-assessment strategies was marginal and could not help researchers decide upon which formative e-assessment strategy that stood out as the most preferred one. Learner satisfaction with different formative e-assessment strategies was positively correlated to each other at various levels but no relationship was found between students' scores and learner satisfaction with formative e-assessment strategies. In the end, the study recommends a sustained and integrated use of all three formative e-assessment strategies (online knowledge survey, online student-generated questions and peer-responses, and electronic reflective journals) in the context of blended courses. The study suggests also further studies that would widen, diversify both the scope and research instruments to investigate learner satisfaction with formative e-assessment strategies.
\end{abstract}

Keywords-Formative e-assessment, student engagement, feedback, learner satisfaction. 


\section{Introduction}

Recent developments in technology have changed in many ways how people work and live. In teaching and learning, technology is changing pedagogical practices, and with the advent of e-learning solutions, the Internet is revolutionizing instructional delivery methods. Higher education institutions seem to be under pressure [1] to partially or wholly move the teaching, learning and assessment activities online. [2] assert that that one of the important pedagogical factors to consider when designing online courses in higher education is to create a learning environment where the content and assessment are embedded and integrated into the learning experience and knowledge building.

Despite the fact that both formative assessment (assessment to support learning) and summative assessment (assessment for accreditation and validation) are important in online courses [3], there has been a tension between them [4]. Summative assessment has been dominating instructional processes in online higher education at the expense of formative assessment [5], [6], [3], [7]. For this reason, some authors (for example [8]) advocate for a shift from focusing heavily on summative assessment practices in order to develop instructional assessment tasks that not only assess the end-product or the performance but also provide ongoing feedback.

Some studies have demonstrated that the effective use of technology can improve and support formative assessment practices [9], [10]. Technology allows students to monitor their understanding whenever and wherever they want [11]. Technology can also support immediate feedback and allow a rapid change of students' misconceptions [5]. Technology helps in speeding up tracking, tracing, storing, processing and visualising students' results as well as actions [11]. In addition, technology can be a "resource-efficient way" to give timely feedback to students [12].

It is important to notice that, amid the progressive increase of using new technologies to support Formative Assessment (FA), the consideration of students' perceptions has a paramount importance. Students' acceptance and attitude towards these technologies seem to be part of the determining factors [13]. Research studies on students' attitude towards online FA [14], [15], [16], [17], [18]) have mainly focused on students' views and attitudes towards online FA with little emphasis on students' satisfaction. Therefore, the present study aims at exploring the student satisfaction with formative e-assessment strategies. This is a retrospective study that looks back at three previous studies about the implementation of formative e-assessment strategies in real classroom settings. We examined how the students perceived formative eassessment strategies (online knowledge survey; online student-generated questions and peer responses; and structured electronic reflective journals) they were involved in.

\section{$2 \quad$ Literature Review}

Studies on student perceptions of formative e-assessment have been contextualised within a growing need to respond to universities' concerns about the effectiveness and 
quality of online courses. Research on student satisfaction with online courses in higher education has involved both graduate and undergraduate students and across diverse populations of students [19]. In the following paragraphs, some of the theoretical approaches and models that have been used to define, understand, and assess the student satisfaction with online courses are reviewed.

The study by [20] that investigated the relationship between the constructs of a web-based learning and student satisfaction, identified five key constructs that predicted the student's perception with online courses: learner relevance, active learning, authentic learning, learner autonomy, and computer technology competence. According to [21], many studies have established that both quantity and quality of student interactions are highly correlated with student satisfaction in most learning environments. Student interaction plays an important role and constitutes one of the major factors that determine the student satisfaction in online course [22].

In their study that examined the satisfaction of students and instructors toward online learning tools and resources, [23] used the Expectancy Confirmation Theory (ECT) and Technology Acceptance Model (TAM). Their study's findings indicated that student expectation was a very important factor that helped the teachers design and develop effective technology-based instructional activities that enhance student learning. By extending the research on the community of inquiry framework [24] to understand online learning, [25] examined the effects of technology on the community of inquiry (social, content and teaching presence issues) and satisfaction with online courses. They specifically examined how the Learning Management System (LMS) provided people with the ability to take actions in an online course and one the major findings was that satisfaction with the LMS predicted course satisfaction.

Previous research studies also focused on some formative e-assessment-related areas such as student perceptions or views, effect, student satisfaction, evaluation, and student attitudes. A university student survey by [26] indicated the students' positive perceptions of an anonymous online peer feedback in formative e-assessment. The students' positive perceptions were also observed in the studies by [27] and [17]. They respectively found out that the students valued the utilization of formative feedback in an online learning environment and perceived the online homework use for formative assessment as useful.

Students' perceptions of the effect of formative e-assessment on their learning have also been investigated. [28] conducted interviews and a student survey to study students' perceptions of a "novel formative assessment" that consisted of involving students solving circuit problems online individually. Compared to a traditional online discussion, the majority of students reported more engagement, more learning, and more interaction with the instructor. In addition, [29] and [30] found out that the students thought their learning was improved as a result of taking part in online formative assessment instructional activities.

Some few research studies that have focused on student satisfaction with formative e-assessment practices suggested that students' high satisfaction with e-assessment [31] and with a web-based formative assessment [32], and a positive and collaborative learning resulting from online peer assessment led students to report strong satisfaction [33]. Research in this area has also focused on the students' evaluation of the 
effectiveness of formative e-assessment [34], [35] and students' attitudes towards different aspects and strategies of online formative assessment [36].

A close look at the research studies highlighted above may lead to two main observations. Firstly, in most cases, these previous studies were not based on the principles of good formative assessment and feedback practice proposed for example by [37] that may result into increased learning benefits when they are applied using technology in teaching and learning process. The second observation that can be drawn from the reviewed research studies is that the focus was put on the formative e-assessment strategies other than the ones the present study is concerned with which are: online knowledge survey, online student-generated questions and peer-responses, and the online reflective electronic journals. These strategies are briefly described in the following paragraphs.

Online knowledge surveys consist of sets of questions that cover the entire content of an [online or blended] course [38]. The students are expected to address these questions, not by providing actual and correct answers, but instead by responding to a rating scale of one's own confidence to respond with competence to each question [39]. Knowledge surveys are used as instructional tools students and teachers can use to analyse the student understanding of the course contents, and organise and review the curricula [40]. Knowledge survey practices can serve formative assessment purposes by providing students with an opportunity to monitor their understanding of the learning material, to know where and when they have deficiencies [39] and provide them with a sense of control over their own learning by making the learning more visible [41].

The use of student-generated questions can promote student learning. Studentgenerated questions can be an effective approach to assessment in online courses [42]. Questioning process is fundamental to intelligent understanding [43] and "a hallmark of self-directed, reflective learners in their ability to ask questions that help direct their learning" [44], p. 522). Students' questions can serve formative assessment purposes by providing instructors with "incidental" opportunities for gathering information about the students' understanding [4]. They can also help students with selfreflection and checking of their understanding throughout the teaching and learning process [45]

Reflective learning journals are the written records that are created by the students as they reflect on their learning, on the critical events or incidents that were involved, or on the student-teacher interactions over a given period of time [46]. According to [47] learning journals can take various forms: they can be highly structured or free, on paper or in electronic forms. As far as formative assessment is concerned, reflective journals help understand the progress of students by providing good opportunities for teachers to gain better insights into how the students think and feel about the course, and the learning progress of the students throughout the courses [48].

The present study aims at expanding and taking to further step the investigation of student experience with formative e-assessment practices. Specific to this study is the measurement of learner satisfaction with formative e-assessment strategies which is driven by "the quality of student engagement" and "the quality of feedback" that seems to be important characteristics of a successful assessment that supports stu- 
dents' learning [49]. According to these authors, the analysis of the quality of student engagement in any successful assessment task should focus on a number of criteria. Those criteria include the sufficiency of assessment tasks, the variation and distribution of assessment tasks across all the course sections, whether assessment tasks are quite engaging: communicating clear and high standards criteria, whether assessment tasks are engaging students in meaningful learning activities (whether they are worth the time and efforts the students spend on them). They argue also that the analysis of the quality of feedback in any successful assessment task should focus on the sufficiency of feedback, the details of feedback, the timeliness of feedback, the appropriateness of feedback to the purpose of assessment task, and the clarity of feedback (whether the feedback clearly describes what the learner is supposed to do). The following research questions guided this study:

- To what extent are students satisfied with the quality of their engagement with formative e-assessment learning activities?

- To what extent are students satisfied with the quality of feedback received in formative e-assessment learning activities?

- Does the student satisfaction differ between and within formative e-assessment strategies?

- Does a relationship exist between the learner satisfaction ratings on formative eassessment strategies and the students' scores?

- How are the learner satisfaction ratings on different formative e-assessment strategies related to each other?

The common denominator for all these research questions is the "learner satisfaction." However, each research question addresses a different aspect of the study as it is illustrated in Figure 1 below:

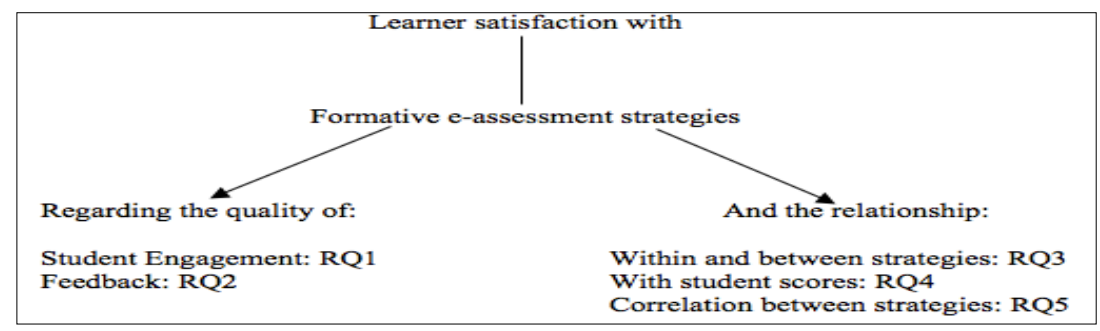

Fig. 1. Relationship between the research questions

\section{$3 \quad$ Methodology}

\subsection{Context of the study}

The present study aims at measuring learner satisfaction with formative eassessment strategies. It is a retrospective account of three studies about the implementation of formative e-assessment strategies in real classroom settings at the Uni- 
versity of Rwanda-College of Education. We examined how the student perceived three formative e-assessment strategies: online knowledge survey, online studentgenerated questions and peer responses, and structured electronic reflective journals.

Online knowledge survey: That was used in [50] study, was used as a formative e-assessment strategy to help students monitor their understanding and progress throughout an enhanced virtual course. Online knowledge surveys (KS) were developed basing on three key elements: learning objectives, module content, and the revised Bloom's Taxonomy of learning objectives [51]. The KS question items were developed using Moodle Feedback module and were sequenced along the four sections of the blended course.

Online student-generated questions and peer responses: Were used as a formative e-assessment strategy in the study by [52]. The student-generated questions and peer-responses were used in the context of the student-based formative e-assessment through peer scaffolding. Students were invited to generate learning material-related questions and to seek responses and support from peers. After each section of the blended course, the student-generated questions and answers were retrieved from Moodle learning management system for analysis by means of an assessment rubric that was structured on three levels of thinking: basic, medium, and high.

Structured electronic reflective journals: Were used as a formative e-assessment strategy in the study by [53] in a blended course. At the end of each course section, the participants were invited to reflect on their learning experience by completing a reflective e-journal. The students' reflective e-journals were analysed by means of a reflection framework and students were categorized into three groups: critical reflectors, reflectors, non-reflectors, and beginners.

\subsection{Participants}

The measurement of student satisfaction with formative e-assessment strategies covered three studies ([50], [52], and [53] that had addressed year three studentteachers $(n=109)$. These students were accessing and engaged with formative eassessment learning tasks that were inbuilt in the blended course (EDC 301: Integration of ICT in Education) that was delivered through the University of Rwanda online learning platform (Moodle).

\subsection{Instruments}

This study used a self-completion questionnaire which facilitates the collection of large amounts of information in a relatively short time from the respondents who have a greater feeling of anonymity and more comfortable in expressing their real feelings [54].

A twenty-seven-item questionnaire was used to measure student satisfaction with formative e-assessment strategies. The respondents were invited to indicate their level of satisfaction with the question items' statements on a range of five-point Likert-type satisfaction scale 
- 5 : Very satisfied,

- 4 : Satisfied,

- 3 : Neither satisfied nor dissatisfied,

- 2 : Dissatisfied,

- 1: Very dissatisfied.

These items were constructed based on "the quality of student engagement" and "the quality of feedback" that [49] consider being the two important characteristics of any successful assessment that supports students' learning.

As this study used a multiple item Likert-scale based questionnaire, we deemed it necessary to determine if the scale was reliable. To determine the level of internal consistency among the questionnaire items, Cronbach's alpha test was run in SPSS for 12 items that measured student satisfaction with e-assessment strategies in terms of the quality of student engagement and for 15 items that measured student satisfaction with e-assessment strategies in terms of the quality of feedback. The Cronbach's alpha was respectively 0.878 and 0.951 for the quality of student engagement items and the quality of feedback items. Since the commonly recommended acceptable level of internal consistency is $\geq 0.70$ [55], the test results indicated a high level of internal consistency for the Likert scale that was used.

\subsection{Data collection procedure}

The questionnaire that was used in this study was made of self-rating questions where a respondent was asked to rate how s/he was satisfied with a statement. A 5point Likert- type scale questionnaire was created using Google Forms and the link was sent to the respondents via email. The questionnaire was pre-tested by asking some of the potential respondents to complete it before it was sent out to the actual research respondents. The pre-test of the questionnaire allowed the researchers to identify some of the eventual flaws within the questionnaire and address them. In this study, 109 electronic questionnaires were sent out. Of these, 108 satisfaction questionnaires were returned and represented an overall response rate of $99 \%$.

\subsection{Data analysis}

Through Google Forms, the respondents' answers were automatically saved onto a computer file at the time of collection. These data were subsequently exported into excel sheets that are compatible with SPSS analysis software using the predefined codes. Descriptive statistics were used first and included the measurement of means and standard deviations. In addition, a Cronbach's alpha reliability test was done to measure the level of internal consistency for the Likert scale that was used. A OneWay ANOVA test was run in SPSS to determine whether there was a significant difference in learner satisfaction between and within the formative e-assessment strategies. Finally, a Pearson's $r$ data analysis was calculated to determine whether there was any relationship between learner satisfaction and students' scores, and between the learner satisfaction ratings on different formative e-assessment strategies. 


\section{$4 \quad$ Results}

\subsection{To what extent are the students satisfied with the quality of their engagement with the formative e-assessment learning activities?}

To answer this question, data collected from 12 items (item number one through item number twelve) of the questionnaire were used. The students were asked to report how they perceived the engagement level of formative e-assessment activities within EDC 301 course. The students were asked to indicate their level of satisfaction with the formative e-assessment tasks in terms of sufficiency of formative $e$ assessment tasks, the variation and coverage, engaging standards and criteria, whether completing assessment tasks was worth the time and efforts the students spent.

In general, the students were satisfied with the quality of every engagement criteria across all the formative e-assessment strategies (see Table 1). The highest level of the Likert satisfaction scale that was used was 5 (very satisfied) and the students' satisfaction mean rating (see Table 1$)$ was $\geq 4.28(\mathrm{SD}=0.70)$.

Table 1. Descriptive Statistics of students' Ratings of satisfaction with formative e-assessment tasks regarding the quality of student engagement

\begin{tabular}{|l|c|c|}
\hline \multicolumn{1}{|c|}{$\mathbf{N}=\mathbf{1 0 8}$} & Mean & Std. Deviation \\
\hline Assessment tasks were varied in online Knowledge survey & 4.64 & 0.60 \\
\hline $\begin{array}{l}\text { Completing the assessment tasks was worth the time and efforts I spent } \\
\text { in online knowledge survey }\end{array}$ & 4.56 & 0.63 \\
\hline Sufficient assessment tasks were provided in online knowledge survey & 4.55 & 0.54 \\
\hline Assessment tasks were engaging enough in online knowledge survey & 4.45 & 0.69 \\
\hline $\begin{array}{l}\text { Completing the assessment tasks was worth the time and efforts I spent } \\
\text { in online student-generated questions }\end{array}$ & 4.38 & 0.67 \\
\hline $\begin{array}{l}\text { Assessment tasks were engaging enough in online student-generated } \\
\text { questions }\end{array}$ & 4.38 & 0.69 \\
\hline Assessment tasks were varied in electronic reflective journals & 4.37 & 0.68 \\
\hline $\begin{array}{l}\text { Sufficient assessment tasks were provided in electronic reflective jour- } \\
\text { nals }\end{array}$ & 4.37 & 0.73 \\
\hline $\begin{array}{l}\text { Completing the assessment tasks was worth the time and efforts I spent } \\
\text { in electronic reflective journals }\end{array}$ & 4.32 & 0.71 \\
\hline Assessment tasks were varied in online student-generated questions & 4.31 & 0.69 \\
\hline Assessment tasks were engaging enough in electronic reflective journals & 4.31 & 0.72 \\
\hline $\begin{array}{l}\text { Sufficient assessment tasks were provided in online student-generated } \\
\text { questions }\end{array}$ & 4.28 & 0.70 \\
\hline
\end{tabular}

If taken separately, there are variations in students' satisfaction with formative eassessment strategies regarding the quality of student engagement. The results show that the respondents were, in most cases, dominantly satisfied with the quality of student engagement in formative e-assessment tasks they completed in knowledge survey. In fact, within knowledge survey, the students' satisfaction mean rating was $4.64(\mathrm{SD}=060)$ for the variation of assessment tasks, $4.56(\mathrm{SD}=0.63)$ for the completion of assessment tasks that was worth the time and efforts the students spent, 
$4.55(\mathrm{SD}=0.54)$ for the sufficiency of assessment tasks, and $4.45(\mathrm{SD}=0.69)$ for the fact that assessment tasks were engaging enough.

The students' satisfaction mean rating was the same for some engagement criteria of formative e-assessment strategies. The mean rating was 4.38 for the completion of assessment tasks that was worth the time and efforts the students spent in online student-generated questions $(\mathrm{SD}=0.67)$ and the fact that assessment tasks were engaging enough $(\mathrm{SD}=0.69)$ in online student-generated questions. The mean rating was also the same (4.37) for both the variation $(\mathrm{SD}=0.68)$ and sufficiency $(\mathrm{SD}=0.73)$ of assessment tasks in electronic reflective journals. This was also observed in the variation of assessment tasks (M: 4.31, $\mathrm{SD}=0.69)$ in online student-generated questions and in the fact that assessment tasks were engaging enough (M: 4.31, SD =072). The results show that, based on the extent to which the students were satisfied with the quality of their engagement, knowledge survey was an e-assessment strategy the students were mostly satisfied with; followed by electronic reflective journals and online student-generated questions.

Two clusters emerged from the analysis of the student satisfaction mean ratings of the quality of student engagement with formative e-assessment tasks. Three formative e-assessment engagement criteria within knowledge survey were included in the first cluster and had the student satisfaction mean rating that was greater than 4.50 . The nine remaining engagement criteria were included in the second cluster with the student satisfaction mean rating of $4.45 \leq \mathrm{M} \geq 4.28$.

\subsection{To what extent are the students satisfied with the quality of feedback received in formative e-assessment learning activities?}

To answer this question, the data collected from 15 items (item number 13 through item number 27) of the questionnaire were used. The students were asked to report how they perceived the quality of feedback within formative e-assessment activities they were involved in. Using a 5-point scale (very satisfied: 5, satisfied: 4, neither satisfied nor dissatisfied (neutral): 3 , dissatisfied: 2 , and very dissatisfied: 1 ), students were asked to indicate their level of satisfaction with the formative e-assessment tasks in terms of the sufficiency of feedback, the details of feedback, the timeliness of feedback, the appropriateness of feedback, and the clarity of feedback.

In general, the students were satisfied with the quality of every feedback criteria across all the formative e-assessment strategies. The highest level of the Likert satisfaction scale that was used was 5 (very satisfied) and the students' satisfaction mean rating (see Table 2 ) was $\geq 4.03(\mathrm{SD}=0.93)$.

If taken separately, there are variations in students' satisfaction with formative eassessment strategies regarding feedback. The results show that the respondents were, in most cases, predominantly satisfied with the quality of feedback of formative eassessment activities they completed in knowledge survey. In fact, knowledge survey takes the first three highest mean ratings for student satisfaction with the quality of feedback. The students' satisfaction mean rating was $4.41(\mathrm{SD}=0.74)$ for the appropriateness of feedback, $4.25(\mathrm{SD}=0.80)$ for the clarity of feedback, and $4.23(\mathrm{SD}=$ 0.73 ) for the timeliness of feedback. 
Table 2. Descriptive statistics of students' ratings of satisfaction with formative e-assessment tasks regarding the quality of feedback received

\begin{tabular}{|l|c|c|}
\hline \multicolumn{1}{|c|}{ N: 108 } & Mean & Std. Deviation \\
\hline $\begin{array}{l}\text { The feedback was appropriate to the purpose of the assignment in online } \\
\text { knowledge survey }\end{array}$ & 4.41 & 0.74 \\
\hline $\begin{array}{l}\text { The Feedback was describing to me what I was supposed to be doing in online } \\
\text { knowledge survey }\end{array}$ & 4.25 & 0.80 \\
\hline The feedback was timely in online knowledge survey & 4.23 & 0.73 \\
\hline $\begin{array}{l}\text { The Feedback was describing to me what I was supposed to be doing in elec- } \\
\text { tronic reflective journals }\end{array}$ & 4.22 & 0.84 \\
\hline $\begin{array}{l}\text { The feedback was appropriate to the purpose of the assignment in electronic } \\
\text { reflective journals }\end{array}$ & 4.21 & 0.90 \\
\hline Sufficient feedback was provided often enough in online knowledge survey & 4.20 & 0.90 \\
\hline The feedback was provided in enough details in online knowledge survey & 4.19 & 0.89 \\
\hline $\begin{array}{l}\text { The feedback was appropriate to the purpose of the assignment in online stu- } \\
\text { dent-generated questions }\end{array}$ & 4.18 & 0.82 \\
\hline The feedback was timely in online student-generated questions & 4.14 & 0.79 \\
\hline $\begin{array}{l}\text { The feedback was provided in enough details in online student-generated ques- } \\
\text { tions }\end{array}$ & 4.13 & 0.86 \\
\hline Sufficient feedback was provided often enough in electronic reflective journals & 4.13 & 0.81 \\
\hline The feedback was timely in electronic reflective journals & 4.13 & 0.83 \\
\hline The feedback was provided in enough details in electronic reflective journals & 4.07 & 0.84 \\
\hline $\begin{array}{l}\text { The Feedback was describing to me what I was supposed to be doing in student- } \\
\text { generated questions }\end{array}$ & 4.06 & 0.78 \\
\hline $\begin{array}{l}\text { Sufficient feedback was provided often enough in online student-generated } \\
\text { questions }\end{array}$ & 4.03 & 0.93 \\
\hline
\end{tabular}

The students' satisfaction mean rating was the same for three feedback criteria of formative e-assessment strategies: enough details of feedback and the sufficiency of feedback in electronic reflective journals with the respective mean ratings of 4.13 (SD $=0.86)$ and $4.13(\mathrm{SD}=0.81)$. The results show that, based on the extent to which the students were satisfied with the quality of feedback, knowledge survey was aneassessment strategy the students were mostly satisfied with; followed by electronic reflective journals and online student-generated questions.

\subsection{Does the student satisfaction differ between and within formative e- assessment strategies?}

The results illustrated in Table 1 and 2 show that there is variation in the extent to which students were satisfied with formative e-assessment strategies. However, to determine whether the differences were statistically significant, the analysis of the results was taken to another level. A One-Way ANOVA test (see Table 3) was run in SPSS assuming the equality of the means for learner total satisfaction scores of the three-formative e-assessment strategies $\left(\mathrm{H}_{0}: \mu_{\text {Knowledge survey }}=\mu_{\text {Online student-generated questions }}\right.$ $\left.=\mu_{\text {Electronic reflective journals }}\right)$ 
Paper-Measuring Learner Satisfaction with Formative e-Assessment Strategies

Table 3. Tests of between-Subjects Effects from one-way repeated measures ANOVA

\begin{tabular}{|l|c|c|c|c|c|}
\hline & Sum of Squares & df & Mean Square & F & Sig. \\
\hline Between Groups & 213.75 & 2 & 106.87 & 3.61 & 0.03 \\
\hline Within Groups & 9502.50 & 321 & 29.60 & & \\
\hline Total & 9716.25 & 323 & & & \\
\hline
\end{tabular}

The one-way between-subjects analysis of variance revealed a reliable effect of learner satisfaction with individual formative e-assessment strategy on the overall learner satisfaction with three formative e-assessment strategies, $F(2,321)=$ $3.61, p=0.03, M S_{\text {error }}=29.60, \alpha=0.05$. Since the $p$ value associated with the $\mathrm{F}$ ratio is less than the $\alpha$ level, then we could reject the null hypothesis that the means for learner total satisfaction scores of the three-formative e-assessment strategies are equal. Thus, student satisfaction was different between and within the formative eassessment strategies, they were involved in. Since the F ratio was statistically significant, we looked at the multiple comparisons output (see Table 4) to analyse the results of a Least Significant Difference (LCD) Post-Hoc tests.

Table 4. Pairwise Comparisons from one-way repeated measures

\begin{tabular}{|l|l|c|c|c|}
\hline \multicolumn{1}{|c|}{ (I) Strategies } & \multicolumn{1}{|c|}{$(\mathbf{J})$ Strategies } & Mean Difference (I-J) & Std. Error & Sig. \\
\hline $\begin{array}{l}\text { Online knowledge } \\
\text { survey }\end{array}$ & $\begin{array}{l}\text { Online student-generated ques- } \\
\text { tions }\end{array}$ & $1.80^{*}$ & 0.74 & 0.02 \\
\cline { 2 - 5 } & Electronic reflective journals & $1.64^{*}$ & 0.74 & 0.03 \\
\hline $\begin{array}{l}\text { Online student-generated } \\
\text { questions }\end{array}$ & Online knowledge survey & $-1.80^{*}$ & 0.74 & 0.02 \\
\cline { 2 - 5 } & Electronic reflective journals & -0.16 & 0.74 & 0.83 \\
\hline $\begin{array}{l}\text { Electronic reflective } \\
\text { journals }\end{array}$ & Online knowledge survey & $-1.64^{*}$ & 0.74 & 0.03 \\
\cline { 2 - 5 } & $\begin{array}{l}\text { Online student-generated ques- } \\
\text { tions }\end{array}$ & 0.16 & 0.74 & 0.83 \\
\hline
\end{tabular}

* The mean difference is significant at the 0.05 level.

The results illustrated in Table 4 show that there was a significant difference in learner satisfaction total score when paired comparisons were conducted between online knowledge survey and online student-generated questions $(\mathrm{p}=0.02)$, online knowledge survey and electronic reflective journals $(\mathrm{p}=0.03)$. However, the paired comparisons did not show a significant difference $(\mathrm{p}=0.83)$ in learner satisfaction total score between online student-generated questions and electronic reflective journals.

\subsection{Does a relationship exist between learner satisfaction ratings on formative e-assessment strategies and the students' scores?}

To measure the relationship between the students' scores on the blended course and the learner satisfaction with formative e-assessment strategies, A Pearson's $r$ correlation coefficient (see Table 5) was run in SPSS. 
Table 5. Correlation between variables

\begin{tabular}{|c|c|c|c|c|c|c|c|c|}
\hline $\mathrm{N}=103$ & Variable & 1 & 2 & 3 & 4 & 5 & 6 & 7 \\
\hline & 1. Students' scores & 1.00 & & & & & & \\
\hline \multirow{2}{*}{$\begin{array}{l}\text { Online Knowledge } \\
\text { Survey }\end{array}$} & $\begin{array}{l}\text { 2. Learner satisfaction with the } \\
\text { quality of student engagement }\end{array}$ & .09 & 1.00 & & & & & \\
\hline & $\begin{array}{l}\text { 3. Learner satisfaction with the } \\
\text { quality of feedback }\end{array}$ & .09 & $.32 * *$ & 1.00 & & & & \\
\hline \multirow{2}{*}{$\begin{array}{l}\text { Online student-generated } \\
\text { questions }\end{array}$} & $\begin{array}{l}\text { 4. Learner satisfaction with the } \\
\text { quality of student engagement }\end{array}$ & .04 & $.30^{* *}$ & $.19^{* *}$ & 1.00 & & & \\
\hline & $\begin{array}{l}\text { 5. Learner satisfaction with the } \\
\text { quality of feedback }\end{array}$ & .12 & $.24^{* *}$ & $.59 * *$ & $.31^{* *}$ & 1.00 & & \\
\hline \multirow[t]{2}{*}{ Electronic reflective journals } & $\begin{array}{l}\text { 6. Learner satisfaction with the } \\
\text { quality of student engagement }\end{array}$ & .09 & $.41^{* *}$ & $.24 * *$ & $.41^{* *}$ & $.26^{* *}$ & 1.00 & \\
\hline & $\begin{array}{l}\text { 7. Learner satisfaction with the } \\
\text { quality of feedback }\end{array}$ & .05 & $.34^{* *}$ & $.54^{* *}$ & $.26^{* *}$ & $.58^{* *}$ & $.43^{* *}$ & 1.00 \\
\hline
\end{tabular}

The students' scores $(\mathrm{M}=69.2, \mathrm{SD}=12.36)$ were correlated with the learner satisfaction ratings on the quality of the student engagement and the quality of feedback within formative e-assessment learning activities. A Pearson's $r$ data analysis showed that there was no correlation between these variables. No relationship was found between the students' scores and the learner satisfaction ratings on the quality of the student engagement and the quality of feedback across all formative e-assessment strategies.

\subsection{How are the student satisfaction ratings on different formative e- assessment strategies related to each other?}

A Pearson's $r$ data analysis (see Table 5) was run in SPSS to measure the relationship between different learner satisfaction ratings on the quality of student engagement and the quality of feedback within formative e-assessment strategies. In general, a Pearson's $r$ data analysis revealed low, moderate, and high positive correlations.

Firstly, the high positive correlation $(.59 \leq r \leq .54)$ was found where the students who reported high satisfaction ratings in one assessment strategy were highly likely to report higher satisfaction ratings in another formative e-assessment strategy. This was observed between the learner satisfaction with the quality of feedback in online knowledge survey and in online student-generated questions, in online studentgenerated questions and electronic reflective journals, and in online knowledge survey and electronic reflective journals.

Secondary, the moderate positive correlation $(.43 \leq r \leq .30)$ was also found where the students who reported high satisfaction ratings in one assessment strategy were moderately likely to report higher satisfaction ratings in another formative eassessment strategy. This was observed for example between the learner satisfaction with quality of student engagement and the quality of feedback in electronic reflective journals, between learner satisfaction with the quality of student engagement in online 
knowledge survey and electronic reflective journals, in online student-generated questions and electronic reflective journals.

Thirdly, there was a low positive correlation $(.26 \leq r \leq .19)$ where the students who reported high satisfaction ratings in one assessment strategy were less likely to report higher satisfaction ratings in another formative e-assessment strategy. This low positive correlation was observed for instance between the learner satisfaction with the quality of student engagement in online student-generated questions and the learner satisfaction with the quality of feedback in electronic reflective journals. In addition, a low positive correlation was revealed between the learner satisfaction with the quality of feedback in online knowledge survey and the learner satisfaction with the quality of student engagement in online-student generated-questions.

\section{Discussion and Conclusion}

In this study, a satisfaction questionnaire was used to measure the learner satisfaction with the formative e-assessment strategies the students were involved in. The construction of the learner satisfaction questionnaire was guided by the 'the quality of student engagement' and 'the quality of feedback' as the two important characteristics of any successful assessment that supports students' learning [49]. The present study's aim was to measure the extent to which the students were satisfied with the quality of the student engagement and the quality of feedback in formative eassessment learning activities and determining any differences in student satisfaction between and within formative e-assessment strategies. In addition, the study aimed to determine whether there was a relationship between the learner satisfaction ratings on formative e-assessment strategies and the students' scores and to examine the relationship between the student satisfaction ratings on different formative e-assessment strategies.

In general, the students were satisfied with the quality of their engagement and the quality of feedback across all the formative e-assessment strategies. These findings concur with some previous studies that concluded that students reported positive perception towards online formative assessment [27], [17] and were highly satisfied [31], [32] with different e-assessment criteria. The present study showed that the students were satisfied with the quality of their engagement with formative e-assessment tasks. These findings are in accordance with [28]' s study where the students reported more engagement, more learning, and more interaction in online formative assessment. Concerning the quality of feedback, the present study indicated that the students were satisfied with the quality of every feedback criterion across all the formative eassessment strategies. This extends [26]'s findings about the students' positive perceptions of online feedback in formative e-assessment.

A Pearson's $r$ data analysis revealed low, moderate, and high positive correlations between student satisfaction ratings on different formative e-assessment strategies. In most cases, it was found out that the students who reported high satisfaction ratings in one assessment strategy were moderately likely to report higher satisfaction ratings in another formative e-assessment strategy. However, unlike some previous research 
studies [56], [57] that established a link between learner satisfaction with various aspects of online or blended learning and performance, this study found no relationship between the students' scores and the learner satisfaction (see also [58]) with formative e-assessment strategies.

A one-way between-subjects analysis of variance revealed that the student satisfaction was different between and within the formative e-assessment strategies. In addition, for both the quality of student engagement and the quality of feedback, the results showed that knowledge survey was an e-assessment strategy that the students were mostly satisfied with; followed by electronic reflective journals and online student-generated questions. In line with [59] who claimed that the use of the Likertscale questionnaire does not allow the researcher to distinguish between spontaneous and constructed responses, the present study's results also showed that the gap between the student satisfaction mean ratings across all formative e-assessment tasks was marginal and could not help researchers clearly discriminate between these formative e-assessment strategies in terms of learner satisfaction.

Thus, as a conclusion, the study recommended a sustained and integrated use of all the three formative e-assessment strategies in the context of blended courses. Further studies were also recommended: there is a need to widen and diversify the scope of the study of the learner satisfaction with formative e-assessment strategies by extending it to more than one course and one classroom and using much more open-ended research instruments that would allow the respondents to freely express their views.

\section{$6 \quad$ References}

[1] A. H. W. van der Zanden, The Facilitating University: Positioning Next Generation Educational Technology. Eburon, 2009. [Online]. Available: uuid:6bf439c3-e62f-4dfe-a1a1289d3b1861e6. [Accessed: January 12, 2018].

[2] A. J. Rourke and K. S. Coleman, "Authentic assessment in e-learning: Reflective and Collaborative writing in the arts", in ASCILITE-Australian Society for Computers in Learning in Tertiary Education Annual Conference, 2011, pp. 1089-1095.

[3] J. W. Gikandi, D. Morrow, and N. E. Davis, "Online formative assessment in higher education: A review of the literature", Computers \& education, vol. 57, no. 4, pp. 2333-2351, 2011. https://doi.org/10.1016/j.compedu.2011.06.004.

[4] D. Wiliam and P. Black, "Meanings and consequences: a basis for distinguishing formative and summative functions of assessment?", British Educational Research Journal, vol. 22, no. 5, pp. 537-548, 1996. https://doi.org/10.1080/0141192960220502

[5] J. Shieh J. and C. Cefai, "Assessment of learning and teaching in higher education: a case analysis of a university in the south of Europe", Malta Review of Educational Research, vol. 11 , no. 1 , pp. $29-47,2017$.

[6] M. Asghar, "The lived experience of formative assessment practice in a British university", Journal of Further and Higher Education, vol. 36, no. 2, pp. 205-223, 2012. https://doi.org/10.1080/0309877X.2011.606901.

[7] M. Northcote, "Online assessment in higher education: the influence of pedagogy on the construction of students' epistemologies', Issues in Educational Research, vol. 13, no. 1, pp. 66-84, 2003. ISSN:1837-6290. 
[8] S. Koç, X. Liu, and P. Wachira, Assessment in online and blended learning environments. Charlotte, NC: Information Age Publishing, Inc., 2015.

[9] JISC, Effective Practice with e-Assessment: An overview of technologies, policies and practice in further and higher education. Joint Information Systems Committee, 2007. [Online]. Available: https://goo.gl/4MA3ts. [Accessed: January 10, 2018].

[10] N. Pachler, C. Daly, Y. Mor, and H. Mellar, "Formative e-assessment: Practitioner cases", Computers \& Education, vol. 54, no. 3, pp. 715-721, 2010. https://doi.org/10.1016/i.compedu.2009.09.032.

[11] E. Rusman, J. Boon, A. Martínez-Monés, M. J. Rodríguez-Triana, and S. Retalis, "Towards the Use of New Methods for Formative e-Assessment of 21st Century Skills in Schools," In Technology Enhanced Formative Assessment (TEFA) workshop, 2013. http://hdl.handle.net/1820/5022

[12] S. Einig, "Supporting Students' Learning: The Use of Formative Online Assessments", Accounting Education, vol. 22, no. 5, pp. 425-444, Oct. 2013. https://doi.org/10.1080/09639284.2013.803868.

[13] A. Popovici and C. Mironov, "Students' Perception on Using eLearning Technologies", Procedia - Social and Behavioral Sciences, vol. 180, no. Supplement C, pp. 1514-1519, May 2015. https://doi.org/10.1016/j.sbspro.2015.02.300.

[14] D. J. Walker, K. Topping, and S. Rodrigues, "Student reflections on formative e-assessment: expectations and perceptions", Learning, Media and Technology, vol. 33, no. 3, pp. 221-234, 2008. https://doi.org/10.1080/17439880802324178.

[15] D. Nicol, "Assessment for learner self-regulation: enhancing achievement in the first year using learning technologies", Assessment \& Evaluation in Higher Education, vol. 34, no. 3, pp. 335-352, 2009. https://doi.org/10.1080/02602930802255139.

[16] J. Dermo, "e-Assessment and the student learning experience: A survey of student perceptions of e-assessment", British Journal of Educational Technology, vol. 40, no. 2, pp. 203-214, 2009. https://doi.org/10.1111/j.1467-8535.2008.00915.x

[17] M. Richards-Babb, R. Curtis, Z. Georgieva, and J. H. Penn, "Student perceptions of online homework use for formative assessment of learning in organic chemistry", Journal of Chemical Education, vol. 92, no. 11, pp. 1813-1819, 2015. https://doi.org/10.1021/acs.jchemed.5b00294.

[18] K. J. Barnard and M. Mostert, "Exploring student perceptions and experiences of ICTenhanced formative assessment in an undergraduate management accounting course", South African Journal of Accounting Research, vol. 29, no. 2, pp. 132-150, 2015. https://doi.org/10.1080/10291954.2015.1006483.

[19] J. K. Sinclaire, "Student satisfaction with online learning: Lessons from organizational behavior", Research in Higher Education Journal, vol. 11, p. 1-20, 2011.

[20] F. Ke and D. Kwak, "Constructs of student-centered online learning on learning satisfaction of a diverse online student body: A structural equation modeling approach", Journal of Educational Computing Research, vol. 48, no. 1, pp. 97-122, 2013. https://doi.org/10.2190/EC.48.1.e.

[21] C. Dziuban, P. Moskal, J. Thompson, L. Kramer, G. DeCantis, and A. Hermsdorfer, "Student Satisfaction with Online Learning: Is It a Psychological Contract?.”, Online Learning, vol. 19, no. 2, p. no. 2, 2015. http://dx.doi.org/10.24059/olj.v19i2.496.

[22] Y.-C. Kuo, A. E. Walker, B. R. Belland, and K. E. Schroder, "A predictive study of student satisfaction in online education programs", The International Review of Research in Open and Distributed Learning, vol. 14, no. 1, pp. 16-39, 2013. http://dx.doi.org/10.19173/irrodl.v14i1.1338. 
[23] J. Keengwe, W. Diteeyont, and A. Lawson-Body, "Student and instructor satisfaction with e-learning tools in online learning environments", International Journal of Information and Communication Technology Education (IJICTE), vol. 8, no. 1, pp. 76-86, 2012. https://dx.doi.org/10.4018/jicte.2012010108.

[24] D. R. Garrison, "Online community of inquiry review: Social, cognitive, and teaching presence issues.", Journal of Asynchronous Learning Networks, vol. 11, no. 1, pp. 61-72, 2007. ISSN: 1092-8235.

[25] B. Rubin, R. Fernandes, and M. D. Avgerinou, "The effects of technology on the Community of Inquiry and satisfaction with online courses", The Internet and Higher Education, vol. 17, pp. 48-57, Apr. 2013. https://doi.org/10.1016/j.iheduc.2012.09.006.

[26] K. A. Thoirs, "Using online peer feedback in formative assessment for medical sonography students teaching: The student view", Radiographer: The Official Journal of the Australian Institute of Radiography, The, vol. 57, no. 2, pp. 26-33, 2010. https://doi.org/10.1002/j.2051-3909.2010.tb00125.x.

[27] C. Halupa and D. U. Bolliger, "Student perceptions on the utilization of formative feedback in the online environment", International Journal of Online Pedagogy and Course Design (IJOPCD), vol. 3, no. 2, pp. 59-76, 2013. https://dx.doi.org/10.4018/ijopcd.2013040104.

[28] G. K. Chung, T. Shel, and W. J. Kaiser, "An exploratory study of a novel online formative assessment and instructional tool to promote students circuit problem solving", The Journal of Technology, Learning and Assessment, vol. 5, no. 6, 2006. [Online]. Available: https://goo.gl/7Md8QT. [Accessed: January 25, 2018].

[29] N. Holmes, "Student perceptions of their learning and engagement in response to the use of a continuous e-assessment in an undergraduate module", Assessment \& Evaluation in Higher Education, vol. 40, no. 1, pp. 1-14, 2015. https://doi.org/10.1080/02602938.2014.881978.

[30] V. Bijol, C. J. Byrne-Dugan, and M. P. Hoenig, "Medical student web-based formative assessment tool for renal pathology", Medical education online, vol. 20, no. 1, pp. 1-7, 2015. https://doi.org/10.3402/meo.v20.26765.

[31] P. Hodgson and M. Y. Pang, "Effective formative e-assessment of student learning: a study on a statistics course", Assessment \& Evaluation in Higher Education, vol. 37, no. 2, pp. 215-225, 2012. https://doi.org/10.1080/02602938.2010.523818.

[32] K. H. Wang, T. H. Wang, W.-L. Wang, and S. C. Huang, "Learning styles and formative assessment strategy: enhancing student achievement in Web-based learning", Journal of Computer Assisted Learning, vol. 22, no. 3, pp. 207-217, 2006. https://doi.org/10.1111/j.1365-2729.2006.00166.x.

[33] V. A. Nguyen, "A peer assessment approach to project based blended learning course in a Vietnamese higher education", Education and Information Technologies, vol. 22, no. 5, pp. 2141-2157, 2017. https://doi.org/10.1007/s10639-016-9539-0.

[34] H. L. Low and S. B. Goh, "An evaluation of the conduct of the online quiz at a public university in Malaysia", In Proc. 2013 IEEE Conference on e-Learning, e-Management and e-Services, 2013, pp. 57-62. https://dx.doi.org/10.1109/IC3e.2013.6735966.

[35] G. M. Velan, P. Jones, H. P. McNeil, and R. K. Kumar, "Integrated online formative assessments in the biomedical sciences for medical students: benefits for learning", $B M C$ Medical Education, vol. 8, no. 1, p. 52, 2008. https://doi.org/10.1186/1472-6920-8-52.

[36] D. Cohen and I. Sasson, "Online quizzes in a virtual learning environment as a tool for formative assessment", Journal of Technology and Science Education, vol. 6, no. 3, pp. 188-208, 2016. http://dx.doi.org/10.3926/jotse.217 
[37] D. Nicol, Transforming Assessment and Feedback: Enhancing Integration and Empowerment in the First Year. Glasgow: Scottish Quality Assurance Agency (QAA) for Higher Education., 2008.

[38] K. R. Wirth and D. Perkins, "Knowledge surveys: An indispensable course design and assessment tool", Innovations in the Scholarship of Teaching and Learning, 2005.

[39] E. Nuhfer and D. Knipp, "The Knowledge Survey: A Tool for All Reasons", To Improve the Academy, vol. 21, no. 1, pp. 59-78, 2003. https://doi.org/10.1002/j.23344822.2003.tb00381.x

[40] P. Bell and D. Volckmann, "Knowledge surveys in general chemistry: confidence, overconfidence, and performance", Journal of Chemical Education, vol. 88, no. 11, pp. 14691476, 2011. https://doi.org/10.1021/ed100328c.

[41] E. F. Barkley and C. H. Major, Interactive Lecturing: A Handbook for College Faculty. San Fransisco, CA: Wiley, 2018.

[42] A. L. Pittenger and J. L. Lounsbery, "Student-Generated Questions to Assess Learning in an Online Orientation to Pharmacy Course", American Journal of Pharmaceutical Education, vol. 75, no. 5, p. 94, Jun. 2011. http://doi.org/10.5688/ajpe75594.

[43] D. R. Sadler, "Formative assessment and the design of instructional systems", Instructional science, vol. 18, no. 2, pp. 119-144, 1989. https://doi.org/10.1007/BF00117714.

[44] C. Chin and D. E. Brown, "Student-generated questions: A meaningful aspect of learning in science", International Journal of Science Education, vol. 24, no. 5, pp. 521-549, 2002. https://doi.org/10.1080/09500690110095249.

[45] B. Y. Wong, "Self-questioning instructional research: A review", Review of Educational Research, vol. 55, no. 2, pp. 227-268, 1985. https://doi.org/10.3102/00346543055002227.

[46] K. Thorpe, "Reflective learning journals: From concept to practice", Reflective practice, vol. 5, no. 3, pp. 327-343, 2004. https://doi.org/10.1080/1462394042000270655.

[47] J. Moon A., Learning journals : a handbook for reflective practice and professional development, 2nd ed. New York: Routledge, 2006.

[48] C. Chan, "Assessment: Reflective Journal, Assessment Resources at Hong Kong University". University of Hong Kong, 2009. [Online]. Available: http://ar.cetl.hku.hk/am ri.htm. [Accessed: Feb., 2, 2018].

[49] G. Gibbs and C. Simpson, "Conditions under which assessment supports students' learning", Learning and teaching in higher education, no. 1, pp. 3-31, 2005. http://eprints.glos.ac.uk/3609/.

[50] B. Bahati, F. Uno, and M. Tedre, "Can Student Engagement in Online Courses Predict Performance on Online Knowledge Surveys?", International Journal of Learning, Teaching and Educational Research, vol. 16, no. 3, pp. 73-87, 2017. https://goo.gl/W91EHP.

[51] D. R. Krathwohl, "A revision of Bloom's taxonomy: An overview”, Theory into practice, vol. 41, no. 4, pp. 212-218, 2010. https://doi.org/10.1207/s15430421tip4104 2.

[52] B. Bahati, U. Fors, and P. Hansen, "Using student-generated questions and peer-responses as a formative e-assessment strategy: Students acting as more knowledgeable others", In Proc. E-Learn: World Conference on E-Learning in Corporate, Government, Healthcare, and Higher Education 2017, Vancouver, British Columbia, Canada, 2017, pp. 108-117. https://www.learntechlib.org/p/181303.

[53] B. Bahati, U. Fors, P. Hansen, and A. Benegusenga, "Using structured learning e-journals as a formative e-assessment strategy: Guiding student-teachers to reflect on their learning through the mirror, microscope, and binoculars.", In Proc. Society for Information Technology \& Teacher Education International Conference 2018, Washington, D.C., United States, 2018, pp. 1124-1133. https://www.learntechlib.org/p/182667. 
Paper-Measuring Learner Satisfaction with Formative e-Assessment Strategies

[54] L. Cargan, Doing Social Research. Lanham, Maryland: Rowman \& Littlefield Publishers, 2007.

[55] B. Johnson and L. Christensen, Educational research: Quantitative, qualitative, and mixed approaches. $5^{\text {th }}$ ed., London, UK: Sage, 2014.

[56] L. Chitkushev, I. Vodenska, and T. Zlateva, "Digital learning impact factors: Student satisfaction and performance in online courses", International Journal of Information and Education Technology, vol. 4, no. 4, pp. 356-359, 2014. https://dx.doi.org/10.7763/IJIET.2014.V4.429.

[57] Y. Dong and A. Lucey, "Relationships between student satisfaction and assessment grades in a first-year engineering unit", In Proc. Design, develop, evaluate: The core of the learning environment. Proceedings of the 22nd Annual Teaching Learning Forum, 7-8 February, 2013. https://goo.gl/smLZLC.

[58] A. Davis, "Measuring Student Satisfaction in Online Math Courses", Doctoral Dissertation, University of Kentucky, Lexington: USA, 2014.

[59] R. Beecham, "Teaching quality and student satisfaction: nexus or simulacrum?", London Review of Education, vol. 7, no. 2, pp. 135-146, 2009. https://doi.org/10.1080/14748460902990336.

\section{$7 \quad$ Authors}

Bernard Bahati is Lecturer in the Department of Foundations, Management and Curriculum Studies at the School of Education of the University of Rwanda-College of Education. He is currently a PhD candidate at Stockholm University, Department of Computer and Systems Sciences (DSV). His research interests encompass a broad area of pedagogical integration of ICTs in teaching and learning. His current research project focuses on technology-enhanced formative assessment. He can be reached at bahatib@dsv.su.se

Uno Fors is a Professor in IT and Learning at Stockholm University, Department of Computer and Systems Sciences (DSV). He is also the Head of the same department. His research interests focus on Simulation and Visualization for learning and assessment. He is especially focused on virtual patients and other virtual encounters for learning in eg. law, teacher education etc. Fors has published more than 150 research publications and has been leading several international and national research projects within these fields. He can be reached at uno@dsv.su.se.

Preben Hansen is an Associate Professor in Human-Computer Interaction and Information Seeking at Stockholm University, Department of Computer and Systems Sciences in the unit of Interaction Design and Design for Learning. He is also the Head of the Design and Collaborative Technologies Group and a Honorary Research Fellow at the University of Illinois, Urbana-Champaign. He can be reached at preben@dsv.su.se

Jalal Nouri currently works at the Department of Computer and Systems Sciences (DSV) at Stockholm University as an Associate Professor (docent). He also coordinates the learning analytics group at the same department. His research belongs to the research field of Technology Enhanced Learning. His current research interests are: learning analytics, artificial intelligence for education, programming education (com- 
putational thinking), mixed reality environments for learning, and 21 st century skills. He can be reached at jalal@dsv.su.se

Evode Mukama holds a Ph.D in Education with a specialization in ICT in education. Mukama is currently an Associate Professor at the University of Rwanda, College of Education. His research interests include knowledge building in computersupported social practice, Open Distance Learning, educational change and curriculum development with ICT as a pedagogical tool. He can be reached at emukama01@gmail.com

Article submitted 2018-06-29. Resubmitted 2018-12-04. Final acceptance 2018-12-04. Final version published as submitted by the authors. 